\title{
The first coordinated observations of mid-latitude $E$-region quasi-periodic radar echoes and lower thermospheric 557.7-nm airglow
}

\author{
T. Ogawa ${ }^{1}$, Y. Otsuka ${ }^{1}$, F. Onoma ${ }^{1}$, K. Shiokawa ${ }^{1}$, and M. Yamamoto ${ }^{2}$ \\ ${ }^{1}$ Solar-Terrestrial Environment Laboratory, Nagoya University, Honohara, Toyokawa, Aichi 442-8507, Japan \\ ${ }^{2}$ Research Institute for Sustainable Humanosphere, Kyoto University, Gokasho, Uji, Kyoto 611-0011, Japan
}

Received: 10 January 2005 - Revised: 19 April 2005 - Accepted: 1 June 2005 - Published: 13 October 2005

Part of Special Issue "SEEK-2 (Sporadic-E Experiment over Kyushu 2)"

\begin{abstract}
We present the first coordinated observations of quasi-periodic $(\mathrm{QP})$ radar echoes from sporadic- $E\left(E_{S}\right)$ field-aligned irregularities (FAIs), OI 557.7-nm airglow, and neutral winds in a common volume over Shigaraki, Japan $\left(34.9^{\circ} \mathrm{N}, 136.1^{\circ} \mathrm{E}\right)$ on the night of 5 August 2002 during the SEEK-2 campaign. QP echo altitudes of $90-110 \mathrm{~km}$ were lower than usual by $10 \mathrm{~km}$, enabling us to make a detailed comparison among QP echoes, airglow intensity, and neutral wind at around $96 \mathrm{~km}$ altitude. Eastward movement of the QP echo regions is consistent with the motions of neutral winds, airglow structures, and FAIs, suggesting that the electrodynamics of $E_{S}$-layers is fundamentally controlled by the neutral atmospheric dynamics. During the QP echo event, the echo altitudes clearly went up (down) in harmony with an airglow enhancement (subsidence) that also moved to the east. This fact suggests that the eastward-moving enhanced airglow region included an upward (downward) component of neutral winds to raise (lower) the altitude of the windshear node responsible for the $E_{s}$ formation. The airglow intensity, echo intensity, and Doppler velocity of FAIs at around $96 \mathrm{~km}$ altitude fluctuated with periods from $10 \mathrm{~min}$ to $1 \mathrm{~h}$, indicating that these parameters were modulated with short-period atmospheric disturbances. Some QP echo regions below $100 \mathrm{~km}$ altitude contained small-scale QP structures in which very strong neutral winds exceeding $100 \mathrm{~m} / \mathrm{s}$ existed. The results are compared with recent observations, theories, and simulations of QP echoes.
\end{abstract}

Keywords. Ionosphere (Ionosphere-atmosphere interactions; Ionospheric irregularities; Mid-latitude ionosphere)

Correspondence to: T. Ogawa

(ogawa@stelab.nagoya-u.ac.jp)

\section{Introduction}

Detailed behavior of 3.2-m field-aligned irregularities (FAIs) in the nighttime mid-latitude $E$-region in summer was presented for the first time by Yamamoto et al. (1991), who used the powerful middle and upper atmosphere (MU) radar at Shigaraki, Japan $\left(34.9^{\circ} \mathrm{N}, 136.1^{\circ} \mathrm{E} ; 25.0^{\circ} \mathrm{N}\right.$ geomagnetic). They found spectacular radar echoes, called "quasi-periodic" (QP) echoes, that appear intermittently at altitudes above $100 \mathrm{~km}$ with periods of 5-20 min from post-sunset to midnight. Since then, some characteristics of the MU radar QP echoes have been revealed by Yamamoto et al. (1992, 1994, 1997) and Ogawa et al. (1995, 1998, 2002), and QP echoes similar to the MU QP echoes have been detected at other locations (e.g. Yamamoto et al., 2005). See a paper by Tsunoda et al. (2004) for radar observations of QP-like echoes prior to the finding of the QP echoes by Yamamoto et al. (1991).

QP echoes from the $E$-region are usually related to sporadic- $E\left(E_{S}\right)$ layers that accompany electron density gradients capable of inducing the gradient-drift instability under the action of the ambient electric field. A recent nonlocal theory by Seyler et al. (2004) predicts that this instability can produce electron density irregularities responsible for radar wave backscatter from both sides of a thin $E_{s}$-layer, superimposed on a background electron density distribution, under constant electric field and/or neutral wind. Strong polarization electric fields associated with an $E_{S}$-layer can rarely excite FAIs through the two-stream instability (Haldoupis et al., 1996). Neutral winds may also play a role in generating FAIs (Kagan and Kelley, 1998). From MU radar observations, Rao et al. (2000) found the new type of QP echoes (lowaltitude QP echoes) at altitudes of $90-100 \mathrm{~km}$ that have vertical wavelengths of $0.6-1.2 \mathrm{~km}$ and periods of $30-90 \mathrm{~s}$ (see also Ogawa et al., 2002). Since then, similar low-altitude QP echoes at other locations have been reported (e.g. Urbina et 


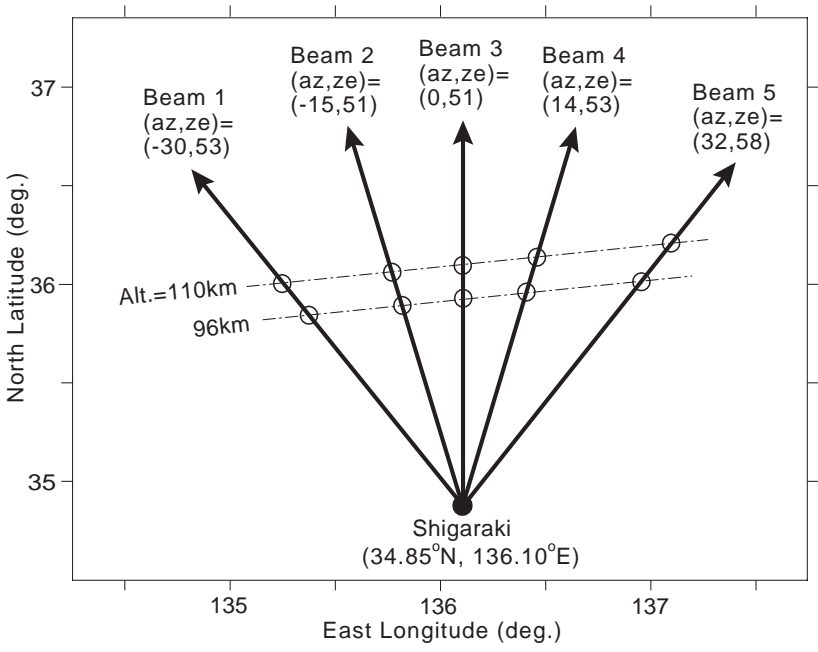

Fig. 1. Bearings (azimuth and zenith) of $5 \mathrm{MU}$ radar beams on geographic coordinates. Points where the beams penetrate 96 and $110 \mathrm{~km}$ altitudes are indicated by white circles.

al., 2000; Urbina et al., 2004 and references therein). Urbina et al. (2004) have pointed out that the gradient-drift instability does not play a primary role in the generation of lowaltitude QP echoes, though a secondary gradient-drift process is supposed to be the cause of radar wave backscatter. The production mechanism of low-altitude QP echoes is still not clear. Atmospheric gravity waves (AGWs) may play a role.

Mid-latitude $E_{s}$-layer is believed to be created by a vertical shear of neutral winds at around $100 \mathrm{~km}$ altitude (e.g. Mathews, 1998). Such a process has been experimentally confirmed through, for example, the SEEK (Sporadic- $E$ Experiment over Kyushu) -1 (Fukao et al., 1998) and SEEK-2 rocket campaigns (Yamamoto et al., 2005) that were successfully conducted in Japan in the summer of 1996 and 2002, respectively. The wind shear may excite the KelvinHelmholtz instability to bring about QP structures in an $E_{S^{-}}$ layer (Larsen, 2000a, 2000b; Bernhardt, 2002). Kagan and Kelley (1998) have suggested that short-period AGWs interacting with an $E_{s}$ may create QP structures (see also Kagan et al., 2000; Kagan, 2002). On the other hand, Cosgrove and Tsunoda $(2002,2003)$ have proposed an azimuth-dependent $E_{s}$ instability to produce QP structures (see also Tsunoda et al., 2004). Their theory predicts a southwestward movement of the QP echo regions with phase fronts aligned NW-SE. Such a movement has been well documented since the discovery of QP echoes by the MU radar (e.g. Yamamoto et al., 1994, 1997; Ogawa et al., 1995, 2002; Hysell et al., 2004; Hussey et al., 2004; Saito et al., 2005). Contrary to this, we show below a case in which QP echo regions move to the east.

Echo intensity, Doppler velocity, and spectral width of QP echoes usually show large temporal and spatial fluctuations (e.g. Yamamoto et al., 1991; Ogawa et al., 1995, 2002), which suggests that these fluctuations are invoked by
AGWs and/or polarization electric fields in an $E_{S}$ (Huang and Kelley, 1996; Horinouchi et al., 2002; Horinouchi, 2004; Yokoyama et al., 2004b, 2005). Strong electric field fluctuations were actually found from the rocket flights during SEEK-1 (Pfaff et al., 1998) and SEEK-2 (Wakabayashi et al., 2005).

Until now, QP echoes and their related FAIs have been studied primarily by means of radars and sounding rockets. However, the relationship between QP echoes (FAIs) and neutral atmospheric disturbances has remained unsolved. To clarify this relationship to some extent, we present the first coordinated observations of MU radar QP echoes, airglow, and neutral winds at around $96 \mathrm{~km}$ over Shigaraki on the night of 5 August 2002 during the SEEK-2 campaign. We use an 557.7-nm all-sky CCD imager and an 557.7-nm Fabry-Perot interferometer (FPI) located at Shigaraki to measure the airglow intensity and neutral winds, respectively.

\section{Experimental setup}

\subsection{The MU radar}

The 46.5-MHz MU radar with a peak power of $1 \mathrm{MW}$ has a sharp antenna beam, and can measure 3.2-m scale $E$-region FAIs by directing the beam northward with zenith angles of $50^{\circ}-60^{\circ}$. Almost simultaneous observations in multidirections are possible by using the capability of high speed beam-swinging with an interpulse period of $1.5 \mathrm{~m} / \mathrm{s}$. We used 5 beams for the observations which will be discussed in this paper. The range and time resolutions were $600 \mathrm{~m}$ and around $20 \mathrm{~s}$, respectively. (See papers by Yamamoto et al. (1991) and Ogawa et al. (1995) for the detailed 5-beam observation technique). Figure 1 shows azimuth and zenith of each beam. The two-way half-power total beam width at these zenith angles is $4.5^{\circ}$ and $2.3^{\circ}$ in the vertical and horizontal planes, respectively. The 5 beams provide an azimuth coverage of $\pm 30^{\circ}$ about geographic north. At $100 \mathrm{~km}$ altitude this azimuth coverage corresponds to an east-west distance of about $155 \mathrm{~km}$. All the beam bearings are within $1.8^{\circ}$ of perpendicular to the geomagnetic field at an altitude of about $100 \mathrm{~km}$. The points where the beams penetrate the 96 and $110 \mathrm{~km}$ altitudes are indicated in Fig. 1 by the white circles. Note that these points are nearly aligned in the geomagnetic east-west direction with separation distances of $30-50 \mathrm{~km}$ between neighboring beams.

Figure 2 depicts detailed configuration of the antenna pattern of beam 3 in the geographical meridian plane that looks due north $\left(5^{\circ} \mathrm{E}\right.$ of geomagnetic north) with an elevation angle of $39^{\circ}$ (Ogawa et al., 2002). Contours of the geomagnetic aspect angle " $A$ ", defined in the upper left corner in the figure, between the radar wave vector and the model geomagnetic field (IGRF85) are also shown. The beam bearing is exactly perpendicular to the geomagnetic field at $100 \mathrm{~km}$ altitude. The geomagnetic aspect angles along the beam bearing are within $90^{\circ} \pm 1^{\circ}$ at ranges of $110-220 \mathrm{~km}$, i.e. at altitudes of $70-135 \mathrm{~km}$. 
2.2 557.7-nm all-sky camera and Fabry-Perot interferometer

An all-sky CCD imager for measuring OI 557.7-nm airglow in the lower thermosphere has been operated at Shigaraki to obtain two-dimensional airglow intensity maps $(512 \times 512$ pixels) every $5.5 \mathrm{~min}$ with an exposure time of $105 \mathrm{~s}$ (Shiokawa et al., 1999). As the 557.7-nm emission occurs mostly at altitudes of $90-100 \mathrm{~km}$ with its peak intensity at around $96 \mathrm{~km}$ (McDade et al., 1986; Iwagami et al., 2003), we assume the emission altitude of $96 \mathrm{~km}$ in this paper. A Fabry-Perot interferometer (FPI) has also been operated at Shigaraki to measure the Doppler shift of $557.7-\mathrm{nm}$ emission at zenith angles of $50^{\circ} \pm 4.75^{\circ}$ and at four azimuthal directions of $\mathrm{N}, \mathrm{S}, \mathrm{E}$, and $\mathrm{W}$, every $15 \mathrm{~min}$, and to obtain neutral wind speed for the first and second fringes independently (Shiokawa et al., 2001). The difference of winds between the both fringes is estimated to be mostly less than $20 \mathrm{~m} / \mathrm{s}$. Note that the horizontal distances between the $\mathrm{N}$ and $\mathrm{S}$ points and between the $\mathrm{E}$ and $\mathrm{W}$ points are about $230 \mathrm{~km}$, so that winds observed by the FPI represent those that are averaged over a large area above Shigaraki.

We operated the MU radar, all-sky imager, and FPI on the nights from 28 July to 6 August (except for 4 August) during SEEK-2 in 2002. Weather conditions, however, were bad, except for 5 and 6 August on which we could obtain simultaneous data from the radar and optical equipment. The minimum altitude of the QP echo region was $90 \mathrm{~km}$ on 5 August and about $100 \mathrm{~km}$ on 6 August, so we analyzed data only on 5 August to see the relationship among QP echoes, airglow, and neutral winds in a common volume.

\section{Observations and analysis}

\subsection{7-nm airglow}

Simultaneous observations of $E$-region FAIs, airglow, and neutral winds were successfully carried out under clear sky conditions after about 20:00 LT on the night of 5 August. Using airglow image data from the all-sky imager, we calculated a deviation of airglow intensity in each pixel of the image. Here the deviation $\Delta I_{558}(t)$ (in $\%$ ) is defined as $\left(I_{558}(t)-I_{0}\right) / I_{0}$, where $I_{558}(t)$ is the absolute intensity (in units of Rayleighs) at time $t$ and $I_{0}$ is the 1-h running average of $I_{558}(t)$. Then the deviations were plotted on geographic coordinates by assuming an emission altitude of $96 \mathrm{~km}$. An example of the deviation map is displayed in Fig. 3, where, for example, the dark airglow region extending from ENE to WSW is discerned. The detailed analysis of the consecutive deviation maps indicates that the averaged motion of the airglow patterns between 20:40 and 22:30 LT was toward SE at about $40 \mathrm{~m} / \mathrm{s}$.

The 5 beam directions of the MU radar shown in Fig. 1 are plotted in Fig. 3. A white circle on each beam represents the position where the beam penetrates the $96 \mathrm{~km}$ altitude. We picked up $I_{558}(t)$ and $\Delta I_{558}(t)$ in the pixel that is closest to

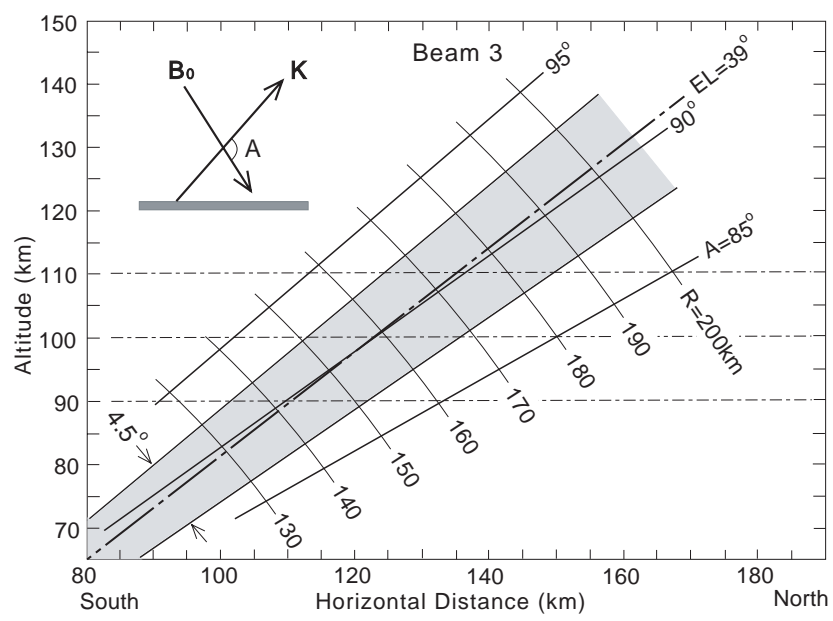

Fig. 2. Configuration of beam 3 in the geographical meridian plane that looks due north with an elevation angle of $39^{\circ}$. The two-way beam width is $4.5^{\circ}$ (shaded) and $2.3^{\circ}$ in the vertical and horizontal planes, respectively. Contours of the geomagnetic aspect angle $(A)$ between the radar wave vector $(\boldsymbol{k})$ and the geomagnetic field vector $\left(\boldsymbol{B}_{0}\right)$ are also shown, together with slant ranges from the MU radar.

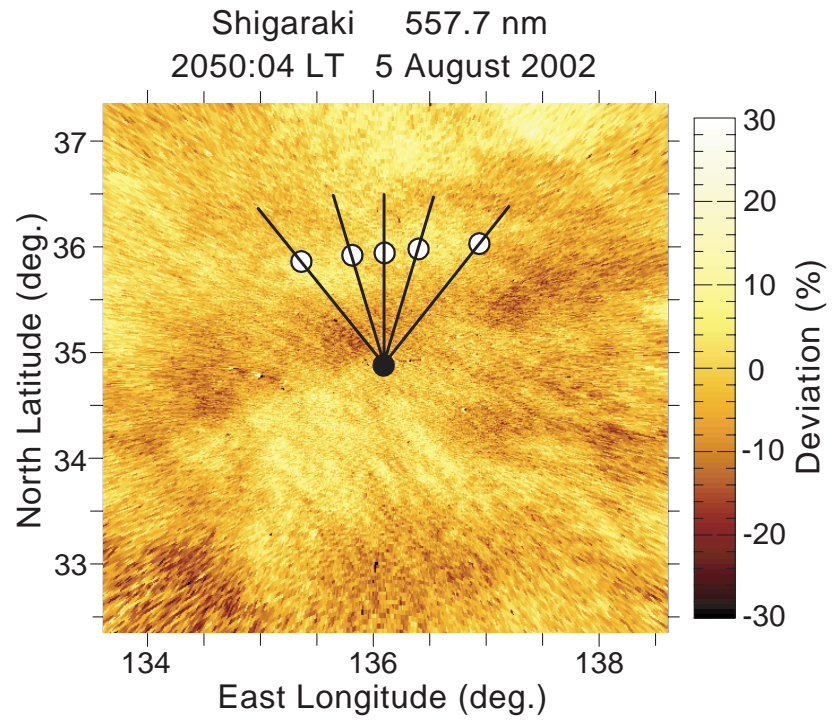

Fig. 3. Map of deviation of 557.7-nm airglow intensity $\left(\Delta I_{558}\right)$ taken at 20:50:04 LT on 5 August 2002. Position of Shigaraki (solid circle) and 5 MU radar beams (solid lines) are also shown. White circles represent positions where the beam penetrates $96 \mathrm{~km}$ altitude.

the white circle. Figure 4a plots temporal variations of these parameters on all the radar beams. The background intensity of $I_{558}$ is about $200 \mathrm{R}$ and the maximum intensity reaches $400 \mathrm{R}$. This indicates an increase in the atomic oxygen density [O] of $26 \%$ of the background density, because $I_{558}$ is approximately proportional to the cube of [O] (McDade et al., 1986). Notice in Fig. 4a that the maximum absolute intensity of $400 \mathrm{R}$ on beams 1 and 5 occurs at 21:37 and 22:14 LT, respectively, indicating an apparent eastward motion of the 


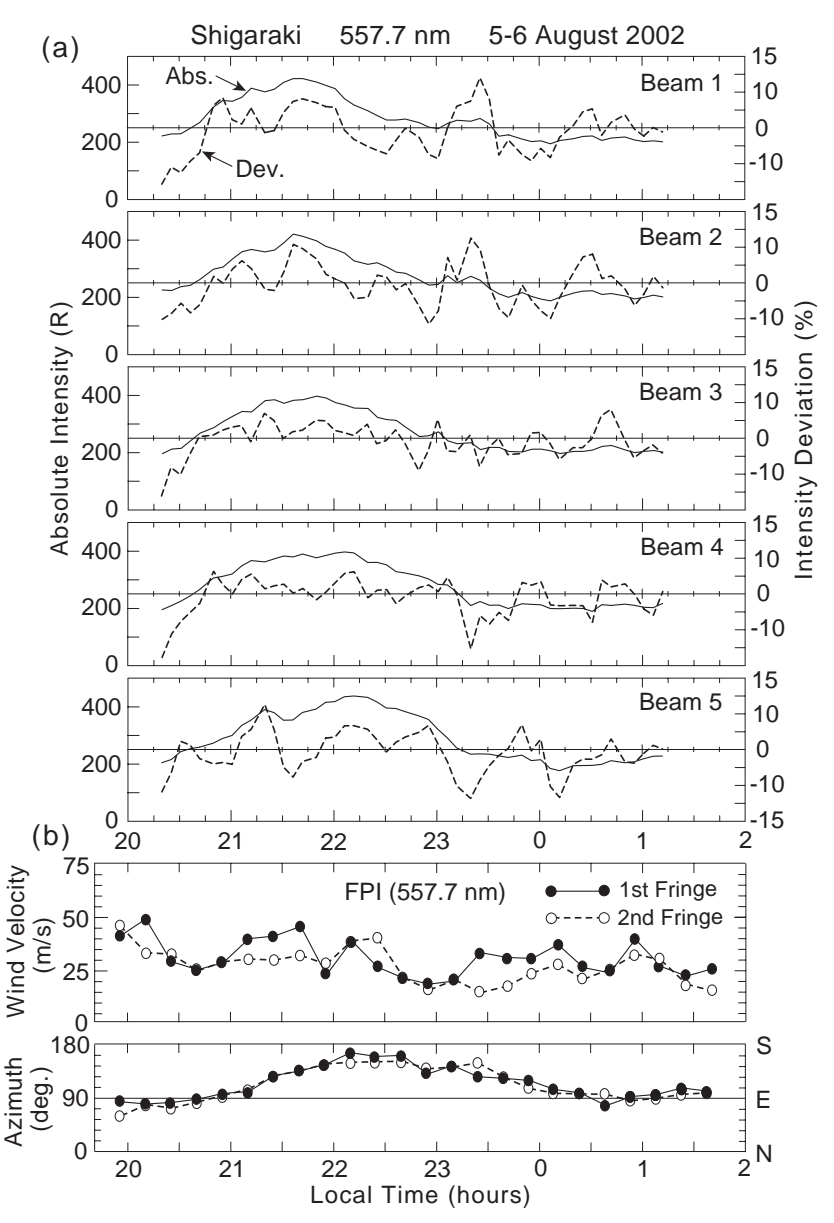

Fig. 4. (a) Temporal variations of absolute intensity $\left(I_{558}\right)$ and deviation of $557.7-\mathrm{nm}$ airglow intensity $\left(\Delta I_{558}\right)$ at around $96 \mathrm{~km}$ altitude (white circles in Fig. 1) on 5 MU radar beams. (b) Neutral wind speed and azimuth (clockwise from geographic north) of the wind vector determined from first and second fringes of the FabryPerot interferometer at Shigaraki.

bright air glow region at about $65 \mathrm{~m} / \mathrm{s}$ along the dot-dashed lines at $96 \mathrm{~km}$ in Fig. 1. This apparent motion corresponds well to the motion of the airglow patterns in Fig. 3 (toward SE at about $40 \mathrm{~m} / \mathrm{s}$ ). The $\Delta I_{558}$ values (dashed curves) in Fig. $4 \mathrm{a}$ fluctuate with periods from $10 \mathrm{~min}$ (= twice the time resolution of $5.5 \mathrm{~min}$ for the airglow measurements) to $1 \mathrm{~h}$. Interestingly, the dashed curves for beams 1 and 4 are similar to those for beams 2 and 5, respectively, with a little time difference. This fact suggests that the airglow is modulated by AGWs with a horizontal scale of about $100 \mathrm{~km}$ (note the separation distances of $40-50 \mathrm{~km}$ between neighboring radar beams), in addition to smaller scales.

Figure $4 \mathrm{~b}$ shows temporal variations of the neutral wind speed and azimuth (clockwise from geographic north) of the wind vector that were determined from the first and second fringes of the FPI. The wind speed at around $96 \mathrm{~km}$ altitude was between 20 and $50 \mathrm{~m} / \mathrm{s}$ while changing slowly its azimuth from the east to the south before about 22:30 LT, and from the south to the east thereafter. The wind may repre-

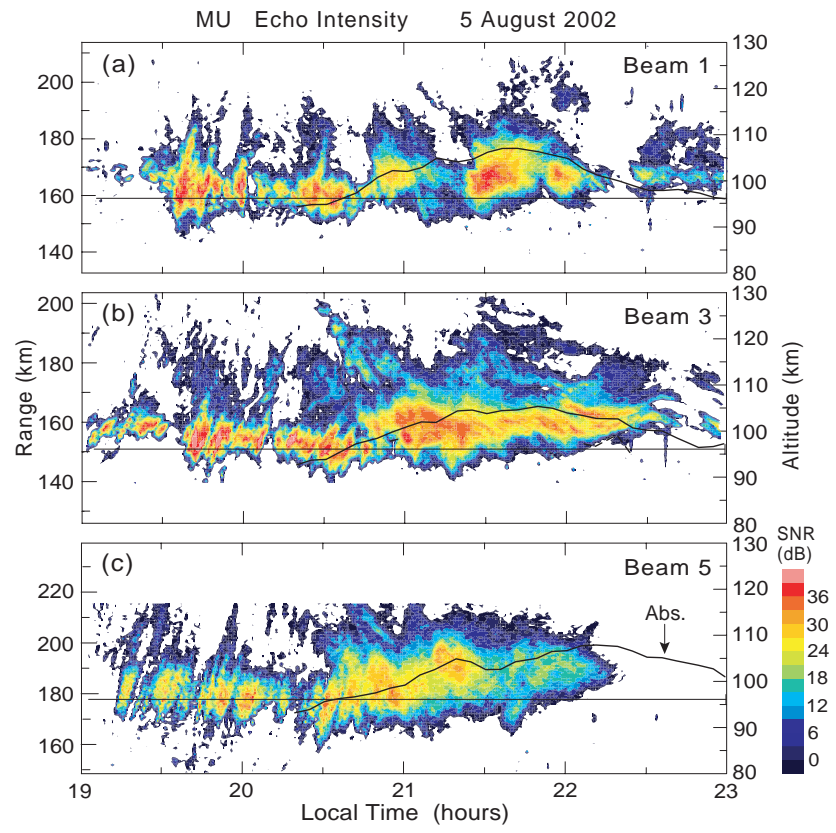

Fig. 5. Range-time-intensity (SNR) plots of MU radar echoes on beams 1, 3 and 5. The right ordinate represents altitudes calculated using slant ranges and zenith angle of each radar beam. Temporal variations of absolute intensity ( $I_{558}$; solid curve) at around $96 \mathrm{~km}$ altitude, shown in Fig. 4a, are also plotted.

sent a semidiurnal tidal wind. The wind speed $(20-50 \mathrm{~m} / \mathrm{s})$ and its azimuth (ENE-SSE) between 20:30 and 22:30 LT are consistent with the eastward motion of both the airglow patterns (Fig. 3) and the most bright airglow region (Fig. 4a).

\section{2 $E$-region radar echoes}

Figure 5 displays range-time-intensity (RTI) plots of signalto-noise ratio (SNR in $\mathrm{dB}$ ) of the MU radar echoes observed on beams 1, 3 and 5 on the night of 5 August. The altitudes shown on the right ordinate were calculated from the steered zenith angle of the radar beam. Typical QP echoes were observed between 19:00 and 22:30 LT on all the beams. The QP echo altitudes are lower by about $10 \mathrm{~km}$ than those previously observed by the MU radar (e.g. Yamamoto et al., 1991; Ogawa et al., 2002). The minimum altitude is about $90 \mathrm{~km}$, which enables us to compare the behavior of the $557.7-\mathrm{nm}$ airglow and FAIs at around $96 \mathrm{~km}$ (horizontal lines in the figure). In fact, an ionogram taken at 20:00 LT at Shigaraki indicates a very strong $E_{s}\left(f_{o} E_{s}\right.$ of about $\left.13 \mathrm{MHz}\right)$ at altitudes lower than $100 \mathrm{~km}$ (not shown). The slopes of the echo striations in the RTI plots are positive (i.e. the echo regions move away from the radar with time) before 20:40 LT for beam 1, 20:45 LT for beam 3, and 20:50 LT for beam 5, and negative after these times. Now we assume that a highdensity plasma blob, in which 3.2-m FAIs are embedded, has a short altitude extent and a horizontal extent narrower than the radar beam width $\left(4.5^{\circ}\right)$. Then Fig. 2 tells us that when the blob motion has a northward (southward) component, the radar detects an echo striation with positive (negative) slope, 

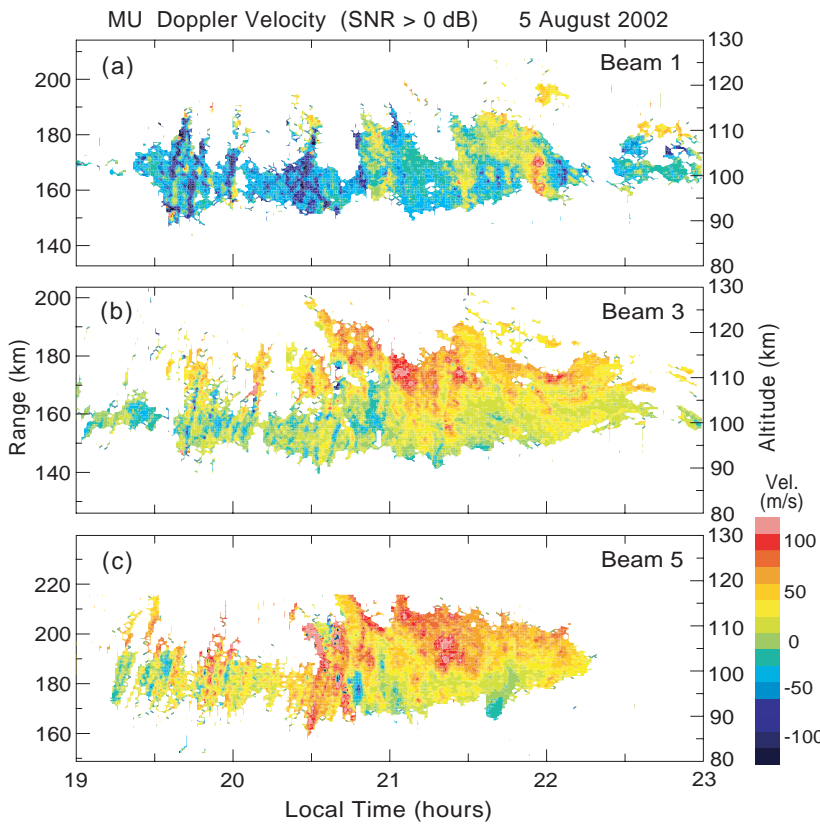

Fig. 6. Range-time-Doppler velocity plots of MU radar echoes with SNRs higher than $0 \mathrm{~dB}$ on beams 1,3 and 5. Plus (minus) sign of Doppler velocity represents motion away from (toward) the radar.

by allowing the geomagnetic aspect sensitivity to be not so severe. Relying on this and consulting with Fig. 1, we estimate that the radar echo regions moved approximately to the NE before about 20:45 LT and to the SE after that. In fact, the neutral wind observed by FPI (Fig. 4b) was ENE before 20:30 LT, and thereafter changed slowly its direction toward the south. This suggests that the meridional winds control the striations of QP echoes; namely, the northward (southward) wind produces positive (negative) range rate (Pan and Tsunoda, 1999). The wind had an eastward component during 20:00-22:30 LT when the QP echoes were observed.

The temporal variations of the absolute airglow intensity $\left(I_{558}\right)$ at around $96 \mathrm{~km}$ altitude shown in Fig. 4a are overlaid in Fig. 5. From a comparison of the radar echoes and $I_{558}$, we point out that on beam 3 (and beam 2; not shown) the altitudes where the echo intensity is high go up and down in harmony with the enhancement and subsidence of $I_{558}$, respectively, though such a behavior is not always clear on beams 1, 4 (not shown), and 5 .

Figure 6 shows range-time-Doppler velocity plots of the MU radar echoes with SNRs higher than $0 \mathrm{~dB}$ on beams 1, 3 and 5 on the night of 5 August. The Doppler velocity $\left(V_{d}\right)$, i.e. the motion of FAIs along radar beam, is given as the first moment of a Doppler spectrum of FAIs. The plus (minus) sign of $V_{d}$ represents motion away from (toward) the radar. The $V_{d}$ values are less than $\pm 150 \mathrm{~m} / \mathrm{s}$. Roughly speaking, the $V_{d}$ signs are negative before 21:30 LT and positive thereafter for beam 1 (Fig. 6a), negative/positive before about 21:00 LT and positive thereafter for beam 3 (Fig. 6b), and almost positive for beam 5 (Fig. 6c). These facts, together with Fig. 1, tells us that the velocity vectors of FAI drifts generally have

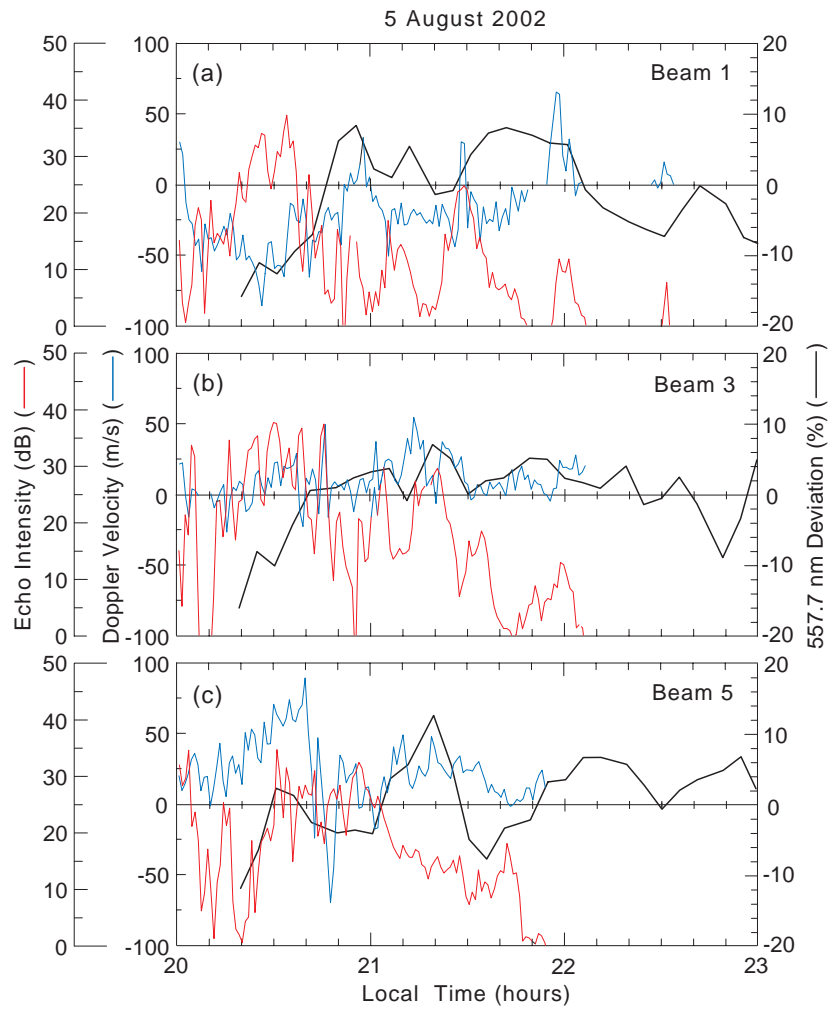

Fig. 7. Temporal variations of echo intensity, Doppler velocity, and deviation of 557.7-nm airglow intensity $\left(\Delta I_{558}\right)$ at around $96 \mathrm{~km}$ altitude (white circles in Fig. 1) on beams 1, 3 and 5.

an eastward component, being qualitatively consistent with the motions of the bright 557.7-nm airglow region (Fig. 4a), neutral winds (Fig. 4b), and FAI region (Fig. 5). It is clear that the $V_{d}$ values on beams 3 and 5 after about 21:00 LT increase gradually with altitude: this is also true for beam 4 (not shown).

Using the $V_{d}$ data from all the radar beams, we estimated a vector of FAI motion $(\boldsymbol{V})$ in the horizontal plane. To this end, we calculated $\bar{V}_{d}$ averaged over 20:00-23:00 LT for altitudes above $100 \mathrm{~km}$ and below that for each beam. Then, assuming that $\bar{V}_{d}$ is a projection of $\boldsymbol{V}$ along the radar beam, we obtained $\boldsymbol{V}$ above $100 \mathrm{~km}\left(\boldsymbol{V}_{1}\right)$ and below that $\left(\boldsymbol{V}_{2}\right)$. The results show that $\boldsymbol{V}_{1}$ is $70 \mathrm{~m} / \mathrm{s}$ with an azimuth of $66^{\circ}$ (clockwise from geographic north), and $\boldsymbol{V}_{2}$ is $53 \mathrm{~m} / \mathrm{s}$ with an azimuth of $88^{\circ}$ (eastward). $\boldsymbol{V}_{2}$ deviates not only from the motion of the airglow structures at around $96 \mathrm{~km}$ (toward SE at about $40 \mathrm{~m} / \mathrm{s}$ ) but also from the neutral wind motions there (toward ENE-SSE at 20-50 m/s in Fig. 4b), maybe because $\boldsymbol{V}_{\mathrm{d}}$ below the 100- km altitude is determined by both $\boldsymbol{E} \times \boldsymbol{B}$ electron drift velocity and neutral winds.

Figure 7 shows temporal variations of echo intensity, $V_{d}$, and $\Delta I_{558}$ at around $96 \mathrm{~km}$ altitude (white circles in Fig. 1) on three radar beams. As is also seen in Fig. $6, V_{d}$ is negative (toward the radar) for beam 1 (Fig. 7a), and mostly positive (away from the radar) for beams 3 (Fig. 7b) and 5 (Fig. 7c), again suggesting the eastward movement of FAIs. As stated before, $\Delta I_{558}$ fluctuates with periods of $10 \mathrm{~min}-1 \mathrm{~h}$. Such 

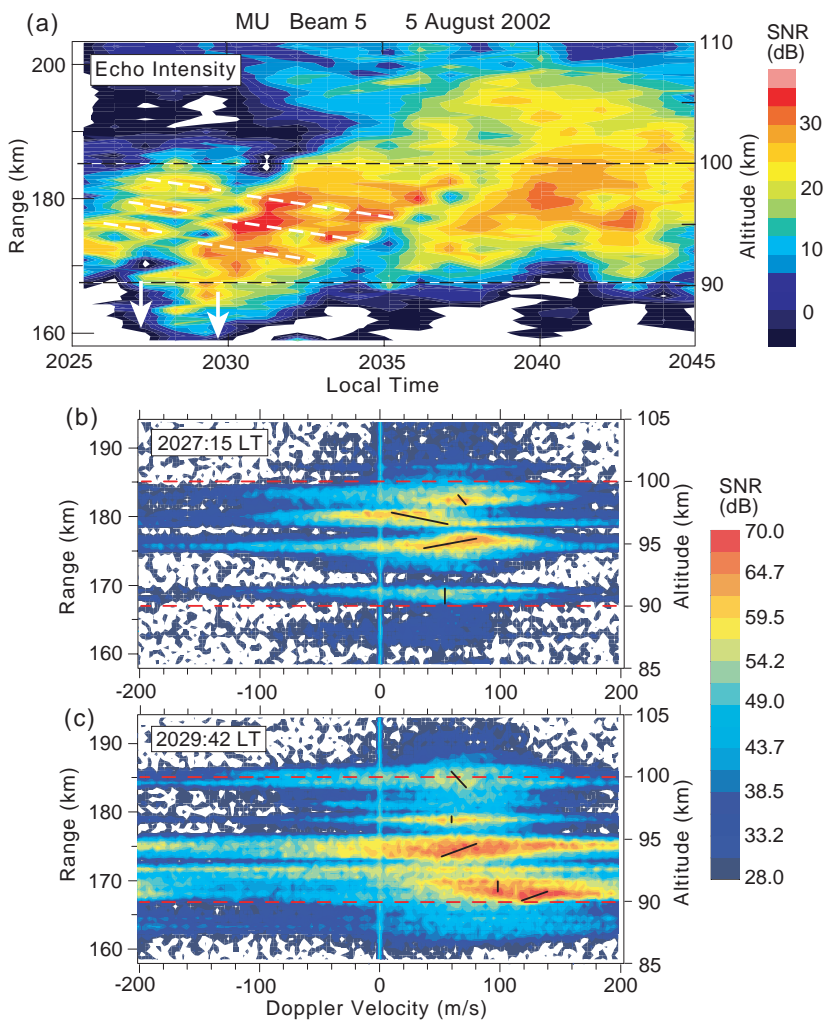

Fig. 8. (a) Range-time-intensity plot of MU radar echoes on beam 5. Range variation of Doppler spectrum at time indicated by an arrow in (a): (b) 20:27:15 LT and (c) 20:29:42 LT. Plus (minus) sign of Doppler velocity represents motion away from (toward) the radar. Solid lines in (b) and (c) connect the peak position of each spectrum

fluctuations are also discerned in the echo intensity and $V_{d}$, suggesting these parameters are modulated by common atmospheric disturbances.

The RTI plot between 20:25 and 20:45 LT in Fig. 5c is enlarged in Fig. 8a, where, as indicated by the white dashedlines, some small-scale QP structures, embedded within the positive striations, with both high echo intensity and weakly negative striation, can be seen between 20:25 and 20:37 LT at altitudes of $87-100 \mathrm{~km}$. This feature means that the eastward-moving plasma blob causing the positive striation includes some small-scale plasma structures that move toward the radar. Range variations of the Doppler spectra obtained at around 20:27 and 20:30 LT are displayed in Figs. 8b and c, respectively. In each figure there are four echo bands with a range separation of about $3 \mathrm{~km}$, corresponding to the altitude separation of about $2 \mathrm{~km}$. The $V_{d}$ values at around $96 \mathrm{~km}$ altitude are between +40 and $+80 \mathrm{~m} / \mathrm{s}$, being higher than the FPI winds (eastward $\sim 30 \mathrm{~m} / \mathrm{s}$ ) in Fig. 4b. Interestingly, very high $V_{d}$ of about $120 \mathrm{~m} / \mathrm{s}$ appears at $90 \mathrm{~km}$ altitude in Fig. 8c. Relying on that $V_{d}$ at this altitude is almost equal to neutral wind speed because of the high collision frequency between electrons and neutrals, we can conclude that very strong neutral winds exceeding $100 \mathrm{~m} / \mathrm{s}$ existed in a lo- cal area at $90 \mathrm{~km}$ altitude. The solid lines in Figs. $8 \mathrm{~b}$ and c connect the peak position of each spectrum. As can be seen, the range (altitude) profiles of $V_{d}$ exhibit strong shears, which may be due to AGWs with sheared wind profiles.

\section{Discussion}

The results are summarized as follows:

1. MU radar QP echoes were observed at altitudes of 90 $110 \mathrm{~km}$ before midnight on 5 August 2002. The minimum altitude $(90 \mathrm{~km})$ of the QP echoes was lower by $10 \mathrm{~km}$ than that of QP echoes previously observed by the MU radar, which made it possible to compare directly the behavior of 3.2-m FAIs, 557.7-nm airglow, and neutral winds at around $96 \mathrm{~km}$ altitude.

2. Motion of QP echo regions had an eastward component. This motion was consistent with the motions of neutral wind, airglow structures, and FAIs. Slopes of QP echo striations in RTI plots were positive before about 20:45 LT and negative after that. This change was caused by a change in the neutral wind direction from ENE to SE.

3. During the QP echo event, airglow intensity at $96 \mathrm{~km}$ altitude was enhanced up to $400 \mathrm{R}$, indicating an increase in the atomic oxygen density of $26 \%$. The motion of the enhanced airglow region had an eastward component of about $65 \mathrm{~m} / \mathrm{s}$, which was consistent with the motion of airglow structures toward SE at about $40 \mathrm{~m} / \mathrm{s}$. Echo altitudes clearly went up and down in harmony with an enhancement and subsidence of airglow intensity, respectively.

4. Airglow structures with periods of $10 \mathrm{~min}$ to $1 \mathrm{~h}$ moved to SE at about $40 \mathrm{~m} / \mathrm{s}$. Echo intensity and Doppler velocity of FAIs at around $96 \mathrm{~km}$ altitude also fluctuated with these periods.

5. Some QP echo regions contained small-scale QP structures with a range separation of $3 \mathrm{~km}$ (altitude separation of about $2 \mathrm{~km}$ ). Doppler spectra of the smallscale structures indicate that FAI velocities at around $96 \mathrm{~km}$ altitude $(+40-+80 \mathrm{~m} / \mathrm{s})$ were higher than FPI wind $(\sim 30 \mathrm{~m} / \mathrm{s})$, and that very strong neutral winds exceeding $100 \mathrm{~m} / \mathrm{s}$ existed in a local area at around $90 \mathrm{~km}$ altitude. Range (altitude) profiles of $V_{d}$ exhibit strong shears.

The present QP echo event is a rare case because it is known that MU radar QP echoes before midnight usually appear above $100 \mathrm{~km}$ altitude (e.g. Yamamoto et al., 1991; Ogawa et al., 2002). In fact, the MU radar observations on the nights of 28 July to 6 August (except for 4 August) during the SEEK-2 campaign showed that the QP echoes appeared more or less on all the nights, and that the altitudes of typical QP echoes before midnight were always above $100 \mathrm{~km}$, except for the 5 August case. 
Regarding the second result finding, the movements of QP echo regions that have been observed by the MU radar are mostly toward SW (e.g. Yamamoto et al., 1994, 1997; Ogawa et al., 1995, 2002). Such a movement has also been detected by the HF and VHF radars in Tanegashima during SEEK-2 (Saito et al., 2005) and at other locations (e.g. Hysell et al., 2004; Hussey et al., 2004; Tsunoda et al., 2004 and references therein). In the present case, however, the QP echo regions moved to the east. This movement is consistent with the results from the simultaneous observations of Doppler velocity, airglow structures, and neutral wind, which suggests that the $E_{s}$-layers, including the 3.2-m FAIs, moved together with the neutral wind. Monitoring of some FM-broadcasting circuits at Wakkanai (northernmost part of Japan) indicated that the $E_{s}$-layers at around $40^{\circ} \mathrm{N}$ on the night of 5 August moved to the east (S. Saito, private communication). Ogawa et al. (1995) reported a case study in which QP echo regions first moved to the east and then to the west. The eastward neutral wind at around $96 \mathrm{~km}$, above which a thin $E_{s}$ is located (as inferred from Fig. 5), together with speculated westward winds above $E_{s}$, is suitable for the generation of $E_{s}$ through the well-known wind-shear mechanism.

Cosgrove and Tsunoda (2002) predicted that a midlatitude $E_{s}$ at a zonal wind-shear node is unstable at night to plane wave distortions. In the Northern Hemisphere the growth rate of the instability is positive (negative) for wave phase fronts with azimuthal alignment in the NW-SE (NE$\mathrm{SW}$ ) direction, and zero for phase fronts aligned $\mathrm{E}-\mathrm{W}$ or N-S (Tsunoda et al., 2004). Then Cosgrove and Tsunoda (2003) showed results from numerical simulations confirming this azimuth-dependent $E_{s}$ instability (see also Yokoyama et al., 2004a). The southwestward movement of QP echo regions with phase fronts aligned NW-SE has been documented in many papers, and seems consistent with the theory of Cosgrove and Tsunoda (2002). However, our QP echoes on 5 August moved to the east, perhaps with phase front alignment in the $\mathrm{N}-\mathrm{S}$ direction, which seems unsuitable for the Cosgrove and Tsunoda theory.

The $V_{d}$ values were mostly less than $\pm 150 \mathrm{~m} / \mathrm{s}$ (Fig. 6). FAIs can be generated by the gradient-drift instability under the combined action of an electric field and electron density gradient, the two-stream instability due to strong electric field, or a wind-driven gradient-drift instability. $V_{d}$ of FAIs produced through the gradient-drift instability is slower than the $\boldsymbol{E} \times \boldsymbol{B}$ electron drift velocity by a factor $(1+\psi)$, where $\psi=v_{e} v_{i} / \omega_{e} \omega_{i} ; v_{e}\left(v_{i}\right)$ is the electron (ion) collision frequency and $\omega_{e}\left(\omega_{i}\right)$ is the electron (ion) cyclotron frequency (e.g. Tanaka and Venkateswaran, 1982). This factor increases rapidly with decreasing altitude; 0.01 at $108 \mathrm{~km}$, 0.1 at $100 \mathrm{~km}, 1.0$ at $93 \mathrm{~km}$, and 10 at $87 \mathrm{~km}$. Hence, $V_{d}$ observed at altitudes lower than, say, $100 \mathrm{~km}$ does not always represent the electron drift velocity: see Ogawa et al. (2002) in detail. The very high $V_{d}$ values exceeding $100 \mathrm{~m} / \mathrm{s}$ at $90 \mathrm{~km}$ altitude (item 5) were observed only on beam 5 but not on other beams (Fig. 6) and are perhaps caused by localized, high-speed neutral winds. Very strong neutral winds exceeding $100 \mathrm{~m} / \mathrm{s}$ at around $90 \mathrm{~km}$ altitude were also observed by Larsen (2000b). Our FPI, however, which is most sensitive to the 557.7-nm airglow at around $96 \mathrm{~km}$ and can observe winds averaged over a large area above Shigaraki, could not detect such a strong wind in a local area at $90 \mathrm{~km}$. Urbina et al. (2004) believe that the gradient-drift instability mechanism does not play a primary role in the generation of low-altitude $(\sim 92 \mathrm{~km})$ radar echo regions drifted at about $100 \mathrm{~m} / \mathrm{s}$ although a secondary gradient-drift process is probably the cause of Bragg-scale electron density waves.

The eastward movement of the isolated bright airglow region is interesting (item 3 ). We suppose that the eastward neutral winds, which accompany vertical wind shears to form $E_{S}$, transported an enhanced [O] from the west to the east, and that this region included an upward (downward) wind component to raise (lower) the altitude of the wind-shear node, namely, the QP echo altitudes.

Regarding the fourth result finding, past QP echo observations demonstrated that the radar echo intensity and Doppler velocity of FAIs usually fluctuates in space and time, perhaps due to AGWs in the neutral atmosphere (e.g. Ogawa et al., 1995). In this paper we have first showed that the temporal and spatial fluctuations of the echo intensity and Doppler velocity associated with QP echoes have counterparts in those of the 557.7-nm airglow in the lower thermosphere. Shortperiod AGWs causing these fluctuations may come from the lower atmosphere, as has first been demonstrated in numerical simulations by Horinouchi (2004). Moreover, recent simulations by Yokoyama et al. (2004b) have shown that AGWs from below modulate an $E_{s}$ to produce wavelike patterns (QP structures) of plasma density, and that southwestward-propagating gravity waves can create the QP echo structures whose phase fronts align from NW to SE, consistent with Cosgrove and Tsunoda's theory (2002). The Yokoyama et al. (2004b) simulations suggest that eastwardpropagating AGWs from below are saturated/dissipated at a critical level, located below a wind-shear node, due to the eastward wind. These eastward-propagating AGWs may account for the south-eastward propagating airglow patterns at $96 \mathrm{~km}$ altitude below the $E_{s}$-layer. Analyzing OI and $\mathrm{OH}$ airglows and $E$-region FAI data from Tanegashima (about $700 \mathrm{~km}$ southwest of Shigaraki) during SEEK-2, Onoma et al. (2005) conclude that the gravity waves seen in the airglow images during FAI events propagated mostly southeastward, which is consistent with our case.

Another candidate for the generation of QP-like echo patterns is the Kelvin-Helmholtz (K-H) instability caused by a sheared neutral wind profile (e.g. Larsen, 2000a, 2000b; Bernhardt, 2002), which does not always require a preferred phase front alignment of echo regions. Bernhardt (2002) have demonstrated from numerical simulations how K-H neutral turbulence evolves nonlinearly to modulate an $E_{S^{-}}$ layer and plasma density in and around $E_{s}$. The vortex structures ("K-H billows") seen in the simulations may account for the fluctuations of airglow intensity, QP echo intensity, QP echo altitudes, and Doppler velocity of FAIs. Sripathi et al. (2003) suggested the K-H instability as a possible source 
for the daytime QP echoes in the lower $E$-region. Shortperiod AGWs that interact with an $E_{s}$ may form the QP structures (e.g. Kagan, 2002). We need more investigations to know which process, K-H billows, AGWs from below, etc., is the primary cause for the fluctuations of the parameters that we observed.

Our fifth result finding strongly suggests that two kinds of atmospheric waves, one causing the positive QP striations and the other causing the negative striations in an RTI plot, might exist in the same region. At this stage we do not know the generation mechanism of these low-altitude echoes, though some hints have been given by Urbina et al. (2004).

\section{Conclusions}

On the night of 5 August 2002 during the SEEK-2 campaign, we made, for the first time, coordinated observations of QP radar echoes, lower thermospheric OI 557.7-nm airglow, and neutral winds in a common volume over Shigaraki. The QP echoes appeared at altitudes of $90-110 \mathrm{~km}$, which were lower by $10 \mathrm{~km}$ than usual QP echo altitudes, enabling us to study the relationship among FAIs, short-period atmospheric disturbances, and neutral winds at around $96 \mathrm{~km}$ altitude. The QP echo regions moved toward the east, contrary to the southwestward movements that have been often observed by the MU radar and radars at other locations. Temporal and spatial fluctuations of echo intensity and Doppler velocity associated with the QP echoes had counterparts in those of the $557.7-\mathrm{nm}$ airglow at around $96 \mathrm{~km}$ in the lower thermosphere.

The eastward movement of the QP echo regions was consistent with the motions of neutral winds, airglow structures, and FAIs, a very reasonable result expected when the electrodynamics of the $E_{s}$ is mainly controlled by the neutral atmospheric dynamics. During the QP echo event, 1) airglow intensity at $96 \mathrm{~km}$ altitude was enhanced up to $400 \mathrm{R}$ (increase of $26 \%$ in $[\mathrm{O}]$ ), 2) the enhanced airglow region moved to the east, and 3) radar echo altitudes clearly went up (down) in harmony with the airglow enhancement (subsidence). These facts suggest that the enhanced airglow region included an upward (downward) wind component to raise (lower) the altitude of the wind-shear node, i.e. of the $E_{s}$ layer. The airglow intensity, echo intensity, and Doppler velocity of FAIs at around $96 \mathrm{~km}$ altitude fluctuated with periods from $10 \mathrm{~min}$ to $1 \mathrm{~h}$, indicating that these parameters were modulated by common atmospheric disturbances. To understand the detailed physical relation between the fluctuations of FAIs and airglow, and the primary cause for the generation of QP structures, we need more coordinated observations of radar echoes, airglow, and neutral winds.

Interestingly, some QP echo regions below $100 \mathrm{~km}$ altitude contained small-scale QP structures in which very strong neutral winds exceeding $100 \mathrm{~m} / \mathrm{s}$ existed. These strong winds may be due to short-period AGWs.
Acknowledgements. The MU radar belongs to and is operated by the Research Institute for Sustainable Humanosphere, Kyoto University. This work was supported by Grant-in-Aid for Scientific Research (11440145) and the 21st Century COE Program (Dynamics of the Sun-Earth-Life Interactive System, No.G-4) of the Ministry of Education, Culture, Sports, Science and Technology of Japan.

Topical Editor M. Pinnock thanks B. P. Rao and J. M. RosadoRoman for their help in evaluating this paper.

\section{References}

Bernhardt, P. A.: The modulation of sporadic-E layers by KelvinHelmholtz billows in the neutral atmosphere, J. Atmos. Sol-Terr. Phys., 64, 1487-1504, 2002.

Cosgrove, R. B. and Tsunoda, R. T.: A direction-dependent instability of sporadic- $E$ layers in the nighttime midlatitude ionosphere, Geophys. Res. Lett., 29(18), 1864, doi:10.1029/2002GL014669, 2002.

Cosgrove, R. B. and Tsunoda, R. T.: Simulation of the nonlinear evolution of the sporadic- $E$ layer instability in the nighttime midlatitude ionosphere, Geophys. Res. Lett., 108(A7), 1283, doi:10.1029/2002JA009728, 2003.

Fukao, S., Yamamoto, M., Tsunoda, R. T., Hayakawa, H., and Mukai, T.: The SEEK (Sporadic-E Experiment over Kyushu) campaign, Geophys. Res. Lett., 25, 1761-1764, 1998.

Haldoupis, C., Schlegel, K., and Farley, D. T.: An explanation of type I radar echoes from the midlatitude $E$-region ionosphere, Geophys. Res. Lett., 23, 97-1000, 1996.

Horinouchi, T., Nakamura, T., and Kosaka, J.: Convectively generated mesoscale gravity waves simulated throughout the middle atmosphere, Geophys. Res. Lett., 29(21), 2007, doi:10.1029/2002GL016069, 2002.

Horinouchi, T.: Simulated breaking of convectively generated mesoscale gravity waves and airglow modulation, J. Atmos. SolTerr. Phys., 66, 755-767, 2004.

Huang, C. S. and Kelley, M. C.: Numerical simulations of gravity wave modulation of midlatitude sporadic $E$ layers, Geophys. Res. Lett., 101, 24 533-24 543, 1996.

Hussey, G. C., Haldoupis, C., Bourdillon, A., Delloue, J., and Wiensz, J. T.: Mid-latitude $E$-region bulk motions inferred from digital ionosonde and HF radar measurements, Ann. Geophys., 22, 3789-3798, 2004,

SRef-ID: 1432-0576/ag/2004-22-3789.

Hysell, D. L., Larsen, M. F., and Zhou, Q. H.: Common volume coherent and incoherent scatter radar observations of mid-latitude sporadic E-layers and QP echoes, Ann. Geophys., 22, 32773290, 2004,

SRef-ID: 1432-0576/ag/2004-22-3277.

Iwagami, N., Shibagaki, T., Suzuki, T., Sekiguchi, H., Takegawa, N., and Morrow, W. H.: Rocket experiment of atomic oxygen density and airglow emission rate in the WAVE2000 campaign, J. Atmos. Sol-Terr. Phys., 65, 1349-1364, 2003.

Kagan, L. M. and Kelley, M. C.: A wind-driven gradient drift mechanism for mid-latitude E-region ionospheric irregularities, Geophys. Res. Lett., 25, 4141-4144, 1998.

Kagan, L. M., Ogawa, T., Fukao, S., and Yamamoto, M.: A role of neutral motions in formation of midlatitude E-region fieldaligned irregularities, Geophys. Res. Lett., 27, 939-942, 2000.

Kagan, L. M.: Effects of neutral gas motion on midlatitude E region irregular structure, J. Atmos. Sol-Terr. Phys., 64, 1479-1486, 2002. 
Larsen, M. F.: A shear instability seeding mechanisms for quasiperiodic radar echoes, J. Geophys. Res., 105, $24931-$ 24 940, 2000a.

Larsen, M. F.: Coqui 2: mesospheric and lower thermospheric wind observations over Puerto Rico, Geophys. Res. Lett., 27, 445-448, $2000 \mathrm{~b}$.

Mathews, J. D.: Sporadic E: current views and recent progress, J. Atmos. Sol-Terr. Phys., 60, 413-435, 1998.

McDade, I. C., Murtagh, D. P., Greer, R. G. H., Dickinson, P. H. G., Witt, G., Stegman, J., Llewellyn, E. J., Thomas, L., and Jenkins, D. B.: ETON2: Quenching parameters for the proposed precursors of $\mathrm{O}_{2}\left(b^{1} \Sigma_{g}^{+}\right)$and $\mathrm{O}\left({ }^{1} \mathrm{~S}\right)$ in the terrestrial nightglow, Planet. Space Sci., 34, 789-800, 1986.

Ogawa, T., Yamamoto, M., and Fukao, S.: Middle and upper atmosphere radar observations of turbulence and movement of midlatitude sporadic $E$ irregularities, J. Geophys. Res., 100, 12 173$12188,1995$.

Ogawa, T., Sekito, N., Nozaki, K., and Yamamoto, M.: Height comparison of midlatitude $\mathrm{E}$ region field-aligned irregularities and sporadic E layer, Geophys. Res. Lett., 25, 1813-1816, 1998.

Ogawa, T., Takahashi, O., Otsuka, Y., Nozaki, K., Yamamoto, M., and Kita, K.: Simultaneous middle and upper atmosphere radar and ionospheric sounder observations of midlatitude E region irregularities and sporadic E layer, J. Geophys. Res., 107(A10), 1275, doi:10.1029/2001JA900176, 2002.

Onoma, F., Otsuka, Y, Shiokawa, K., Ogawa, T., Yamamoto, M., Fukao, S., and Saito, S.: Relationship between propagation direction of gravity waves in $\mathrm{OH}$ and $\mathrm{OI}$ airglow images and VHF radar echo occurrence during the SEEK-2 campaign, Ann. Geophys., 23, 2385-2390, 2005.

Pan, C. J. and Tsunoda, R. T.: Semidiurnal behavior of quasiperiodic echoes in the midlatitude Es region observed with the Chung-Li VHF radar, Geophys. Res. Lett., 26, 2621-2624, 1999.

Pfaff, R., Yamamoto, M., Marionni, P., Mori, H., and Fukao, S.: Electric field measurements above and within a sporadic- $E$ layer, Geophys. Res. Lett., 25, 1769-1772, 1998.

Rao, P. B., Yamamoto, M., Uchida, A., Hassenpflug, I., and Fukao, S.: MU radar observations of kilometer-scale waves in the midlatitude lower E-region, Geophys. Res. Lett., 27, 3667-3670, 2000.

Saito, S., Marumoto, M., Yamamoto, M., Fukao, S., and Tsunoda, R. T.: Radar observations of field-aligned plasma irregularities in the SEEK-2 campaign, Ann. Geophys., 23, 2307-2318, 2005.

Seyler, C. E., Rosanda-Román, J. M., and Farley, D. T.: A nonlocal theory of the gradient-drift instability in the ionospheric $E$-region plasma at mid-latitudes, J. Atmos. Sol-Terr. Phys., 66, 1627-1637, 2004.

Shiokawa, K., Katoh, Y., Satoh, M., Ejiri, M. K., Ogawa, T., Nakamura, T., Tsuda, T., and Wiens, R. H.: Development of optical mesosphere thermosphere imagers (OMTI), Earth Planets Space, 51, 887-896, 1999.

Shiokawa, K., Kadota, T., Ejiri, M. K., Otsuka, Y., Katoh, Y., Satoh, M., and Ogawa, T.: Three-channel imaging Fabry-Perot interferometer for measurement of midlatitude airglow, Appl. Opt., 40, 4286-4296, 2001.
Sripathi, S., Patra, A. K., Sivakumar, V., and Rao, P. B.: Shear instability as a source of the daytime quasi-periodic radar echoes observed by the Gadanki VHF radar, Geophys. Res. Lett., 30(22), 2149, doi:10.1029/2003GL017544, 2003

Tanaka, T. and Venkateswaran, S. V.: Characteristics of fieldaligned $E$-region irregularities over Iioka $\left(36^{\circ} \mathrm{N}\right)$, Japan-I, J. Atmos. Terr. Phys., 44, 381-393, 1982.

Tsunoda, R. T., Cosgrove, R. B., and Ogawa, T.: Azimuthdependent $E$ s layer instability: A missing link found, J. Geophys. Res., 109, A12303, doi:10.1029/2004JA010597, 2004.

Urbina, J., Kudeki, E., Franke, S. J., Gonzalez, S., Zhou, Q., and Collins, S. C.: $50 \mathrm{MHz}$ radar observations of mid-latitude Eregion irregularities at Camp Santiago, Puerto Rico, Geophys. Res. Lett., 27, 2853-2856, 2000.

Urbina, J., Kudeki, E., Franke, S. J., and Zhou, Q.: Analysis of a mid-latitude E-region LQP event observed during the Coqui 2 Campaign, Geophys. Res. Lett., 31, L14805, doi:10.1029/2004GL020031, 2004

Wakabayashi, M., Ono, T., Mori, H., and Bernhardt, P. A.: Electron density and plasma wave measurement in mid-latitude sporadicE layer observed during the SEEK-2 campaign, Ann. Geophys., 23, 2335-2345, 2005

Yamamoto, M., Fukao, S., Woodman, R. F., Ogawa, T., Tsuda, T., and Kato, S.: Mid-latitude $E$-region field-aligned irregularities observed with the MU radar, J. Geophys. Res., 96, $15943-$ 15 949, 1991.

Yamamoto, M., Fukao, S., Ogawa, T., Tsuda, T., and Kato, S.: A morphological study of mid-latitude $E$-region field-aligned irregularities observed with the MU radar, J. Atmos. Terr. Phys., 54, 769-777, 1992.

Yamamoto, M., Komoda, N., Fukao, S., Tsunoda, R. T., Ogawa, T., and Tsuda, T.: Spatial structure of the $E$ region field-aligned irregularities revealed by the MU radar, Radio Sci., 29, 337-347, 1994.

Yamamoto, M., Fukao, S., Tsunoda, R. T., Igarashi, K., and T. Ogawa, T.: Preliminary results from joint measurements of $E$ region field-aligned irregularities using the MU Radar and the frequency-agile radar, J. Atmos. Sol-Terr. Phys., 59, 1655-1663, 1997.

Yamamoto, M., Fukao, S., Tsunoda, R. T., and Hayakawa, H.: SEEK-2 (Sporadic-E Experiment over Kyushu II) - Project outline and significance, Ann. Geophys., 23, 2295-2305, 2005.

Yokoyama, T., Yamamoto, M., Fukao, S., and Cosgrove, R. B. Three-dimensional simulation on generation of polarization electric fields in the midlatitude $E$-region ionosphere, J. Geophys. Res., 109(A01309), doi:10.1029/2003JA010238, 2004a.

Yokoyama, T., Horinouchi, T., Yamamoto, M., and Fukao, S.: Modulation of the midlatitude ionospheric $E$ region by atmospheric gravity waves through polarization electric field, J. Geophys. Res., 109, A12307, doi:10.1029/2004JA010508, 2004b.

Yokoyama, T., Yamamoto, M., and Fukao, S.: Numerical simulation of midlatitude ionospheric $E$ region based on the SEEK and the SEEK-2 observations, Ann. Geophys., 23, 2377-2384, 2005. 